\title{
Darf ich zusätzlich Privatpatienten behandeln?
}

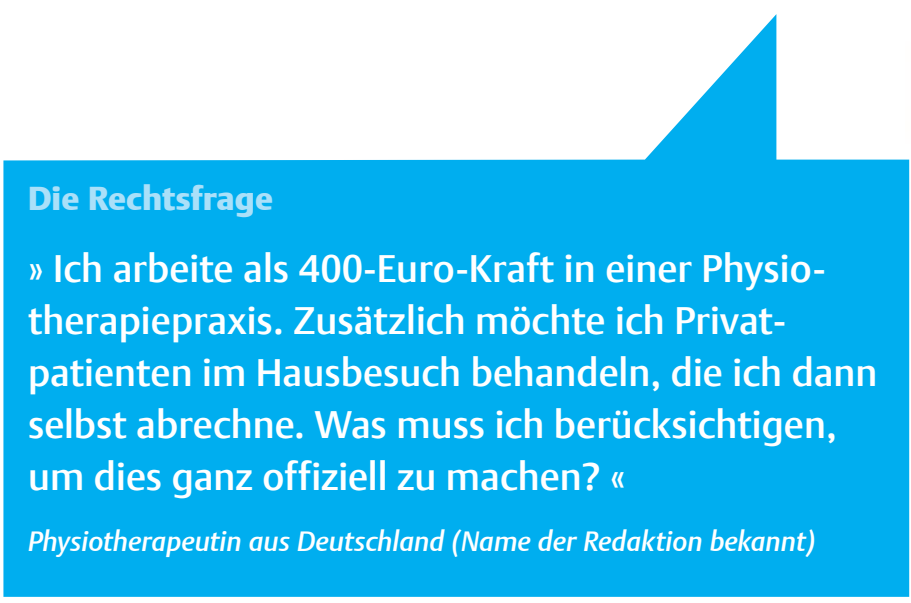

Die Antwort unseres Experten

Diese Frage ist unter zwei Gesichtspunkten zu betrachten: Erstens gilt es zu klären, ob die Therapeutin ihren 400-Euro-Job arbeitsrechtlich aufs Spiel setzt. Zweitens geht es darum, welche Voraussetzungen sie für die Abrechnung erfüllen muss.

Zunächst muss die Physiotherapeutin mit ihrem Arbeitgeber klären, ob er mit einer derartigen Nebentätigkeit einverstanden ist. Da auch er Privatpatienten im Hausbesuch behandelt, tritt sie in Konkurrenz zu ihm. Und die Konkurrenztätigkeit eines Arbeitnehmers rechtfertigt eine fristlose Kündigung. Eine vorherige Abmahnung ist in der Regel nicht erforderlich. Ich rate der Leserin darum, mit dem Arbeitgeber abzugrenzen, welche Patienten sie im Rahmen des Arbeitsverhältnisses und welche sie selbstständig behandeln kann. Die Regelung könnte zum Beispiel beinhalten, dass sie im Rahmen des Arbeitsverhältnisses nur in den Praxisräumen und selbstständig nur im Hausbesuch behandelt.

Da die beabsichtigte Tätigkeit sehr eng an der vertraglichen Tätigkeit liegt, emp- fehle ich zu Nachweiszwecken dringend eine schriftliche Vereinbarung.

Die Einkünfte aus der Nebentätigkeit werden in diesem Fall zu Einkünften aus einer selbstständigen Tätigkeit. Diese muss die Fragestellerin beim Finanzamt anmelden. Auch das Gesundheitsamt und die Berufsgenossenschaft muss sie darüber informieren. Wichtig ist zudem der Abschluss einer Berufshaftpflichtversicherung, falls einmal ein Schaden eintritt. Des Weiteren giltes, die selbstständige(Neben-) Tätigkeit bei der gesetzlichen Rentenversicherung anzukündigen und ggf. in den ersten drei Jahren die Befreiung von der Versicherungspflicht zu beantragen.

Die Behandlung von Privatpatienten ist grundsätzlich nicht an bestimmte Räumlichkeiten gebunden. Empfehlenswert ist die Einhaltung der Standards entsprechend der gesetzlichen Krankenversicherung. Die Abrechnung auf Verordnung erfolgt dann nach den allgemeinen Grundsätzen.

Für die selbstständige Abrechnung von Patienten, die gesetzlich krankenversichert sind, benötigt die Therapeutin laut Sozialgesetzbuch eine Zulassung. Voraussetzung dafür sind eigene Praxisräume.

Alternativ zur Nebentätigkeit wäre für die Leserin eventuell auch eine freie Mitarbeit überlegenswert. Bei einer entsprechenden Vereinbarung mit ihrem Arbeitgeber könnte sie ihr Vorhaben eines selbstständigen Nebenerwerbs verwirklichen und gleichzeitig über feste Aufträge in der Praxis ihr Grundeinkommen von 400 Euro sichern.

Karsten Bossow

\section{$\Rightarrow$ Wirft auch Ihr Berufsalltag rechtliche Fragen auf? Dann schreiben Sie an Simone.Gritsch@thieme.de.}

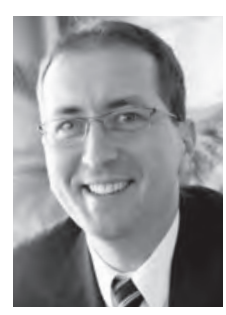

Karsten Bossow ist seit 1999 Rechtsanwalt mit den Tätigkeitsschwerpunkten Arbeits-, Medizin- und Sozialrecht. Seit 2003 ist er Fachanwalt für Arbeitsrecht und seit 2010 Fachanwalt für Medizinrecht. 